\title{
Warm Ocean Accelerating Tropical Cyclone Hagibis (2019) through Interaction with a Mid-Latitude Westerly Jet
}

\author{
Kosuke Ito and Hana Ichikawa \\ Department of Physics and Geosciences, University of the Ryukyus, Okinawa, Japan
}

\begin{abstract}
One of the remarkable environmental characteristics of tropical cyclone (TC) Hagibis (2019) was the positive sea surface temperature (SST) anomaly observed in the western North Pacific Ocean. In this study, an ensemble-based sensitivity experiment was conducted with a nonhydrostatic model, focusing on the impact of SST on TC motion. The TC with the analyzed SST (warm run) moved faster near mainland Japan than with the lowered SST (cold run), as the TC in the warm run was embedded earlier in the mid-latitude westerly jet located to the north than that in the cold run. The TC displacement was consistent with the large decrease of geopotential height at $500-\mathrm{hPa}(\mathrm{Z} 500)$ in the north of TC Hagibis during the warm run. Further investigation showed that the approach to the westerly jet presumably induced the low local inertial stability as well as the southwesterly vertical wind shear enhancing the upward mass flux in the north of the TC. They led the enhanced upper-tropospheric northward outflow from the TC energized by the warm SST, and it resulted in the decrease of the Z500 in the north. This study suggests that warm SST can affect TC tracks through interaction with mid-latitude westerly jets.

(Citation: Ito, K., and H. Ichikawa, 2020: Warm ocean accelerating tropical cyclone Hagibis (2019) through interaction with a mid-latitude westerly jet. SOLA, 17A, 1-6, doi:10.2151/sola.17A001.)
\end{abstract}

\section{Introduction}

Tropical cyclone (TC) Hagibis (2019) formed east of Guam on 5 October and achieved its peak intensity of $915 \mathrm{hPa}$ during 7-10 October. After approaching to the mid-latitude westerly jet, TC Hagibis made landfall in Japan on 12 October 2019 and caused tremendous destruction due to the torrential rainfall and strong winds. In terms of effective disaster control measures for upcoming similar disasters, the impact of various environmental factors on TCs should be elucidated.

One of the characteristic environmental conditions of TC Hagibis was high sea surface temperature (SST) over its track, before its landfall. Therefore, it is important to quantify the impact of this SST anomaly. It is well-known that the TC intensity and volume of rainfall are sensitive to SST (Emanuel 1986; Knutson et al. 2010); however, recent studies have shown that the TC tracks are also sensitive to SST in certain cases. Katsube and Inatsu (2016) and Sun et al. (2017) have shown that warmer SSTs tend to promote earlier northward recurvature of TCs in the western North Pacific Ocean (WNP). Sun et al. (2017) ascribed this result to the retreat of the subtropical high, with its high SST conditions. With a simplified linear baroclinic model, Katsube and Inatsu (2016) interpreted this track change as being the wellknown subtropical thermal response documented by Hoskins and Karoly (1981).

As TC Hagibis (2019) brought about devastating damages, it is important to examine whether the track of TC Hagibis was influenced by the observed SST anomaly and investigate which relevant mechanism(s) can explain the resultant track changes. Consequently, we conducted a set of ensemble simulations by altering the SST, using the Japan Meteorological Agency Non-

Corresponding author: Kosuke Ito, University of the Ryukyus, 1 Sembaru, Nishihara 903-0213, Japan. E-mail: itokosk@sci.u-ryukyu.ac.jp. hydrostatic Model (JMA-NHM; Saito 2012; Saito et al. 2006).

The remainder of the paper is organized as follows. Section 2 describes the numerical setting. Section 3 presents analysis of the simulated results, and we summarize our conclusions in Section 4. While we focus on the track of TC Hagibis (2019), supplemental material A briefly describes the impact of SST on the rainfall amount.

\section{Methods}

The JMA-NHM uses a horizontally explicit and vertically implicit scheme as a dynamical core, with six-category bulk microphysics (Ikawa and Saito 1991), a modified Kain-Fritsch convective scheme (Kain and Fritsch 1990), a clear-sky radiation scheme (Yabu et al. 2005), and a cloud radiation scheme (Kitagawa 2000). Boundary layer turbulence is determined by the MellorYamada-Nakanishi-Niino level-3 closure model (Nakanishi and Niino 2004).

Figures $1 \mathrm{a}$ and $1 \mathrm{~b}$ show that the analyzed SST from the Merged Satellite and In-situ Data Global Daily SST (MGDSST; Kurihara et al. 1993) was much higher in the WNP than the daily climatological mean value (defined as the mean value of MGDSST during 1989-2018) on 7 October 2019. We conducted two experiments to evaluate the impact of the positive SST anomaly. In one experiment, we employed the MGDSST as the initial SST (referred to as the warm run), whereas in the other experiment we replaced the initial SST with the climatology in the WNP (referred to as the cold run). More specifically, the SST in the cold run was calculated as follows:

$$
\begin{aligned}
& \operatorname{SST}_{\text {cold }}(x, y) \\
& = \begin{cases}\operatorname{SST}_{\text {clim }}(x, y), & d<1.0 \\
(1-\alpha) \operatorname{SST}_{\text {clim }}(x, y)+\alpha \operatorname{SST}_{\text {warm }}(x, y), & 1.0 \leq d<1.2 \\
\operatorname{SST}_{\text {warm }}(x, y), & 1.2 \leq d\end{cases}
\end{aligned}
$$

where

$$
\begin{aligned}
& d=\sqrt{\left(\frac{x-165^{\circ} \mathrm{E}}{40^{\circ}}\right)^{2}+\left(\frac{y-5^{\circ} \mathrm{N}}{30^{\circ}}\right)^{2}}, \\
& \alpha=5.0(d-1.0),
\end{aligned}
$$

Herein, $\mathrm{SST}_{\text {clim }}$ is the daily climatological mean value of the SST. $\mathrm{SST}_{\text {warm }}$ and $\mathrm{SST}_{\text {cold }}$ represent the SST used in the warm and cold runs, respectively. The difference between $\mathrm{SST}_{\text {warm }}$ and $\mathrm{SST}_{\text {cold }}$ is displayed in Fig. 1c.

The domain was discretized into $1601 \times 1601$ grid points centered at $135^{\circ} \mathrm{E}$ and $30^{\circ} \mathrm{N}$ with a $5-\mathrm{km}$ grid spacing. There were 30 vertical layers, with the model top of $22 \mathrm{~km}$. Our main experimental period was set to six days from 1200 UTC 7 October through 1200 UTC 13 October. The time step was $24 \mathrm{~s}$. The TC's center position was defined as the location of the minimum sea-level pressure. To obtain reliable results, a ten-member ensemble simulation was conducted both for the warm run and the cold run. The initial perturbations of temperature and the horizontal wind vector were taken from the JMA global model-based ensemble, with a $2.5^{\circ}$ grid spacing. For the purposes of our discussion, we will mainly focus on the ensemble-mean state, unless otherwise noted.

For interpretation, we will calculate the local inertial stability, 
(a) SST(Warm)

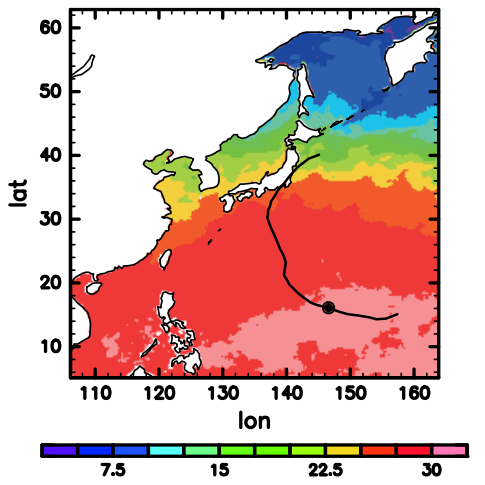

(b) SST(Warm) minus SST(Clim)

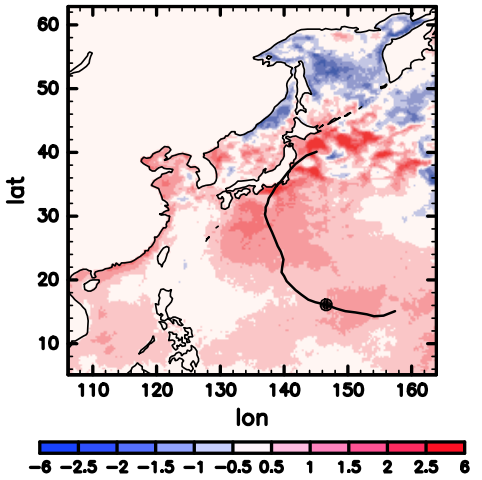

(c) SST(Warm) minus SST(Cold)

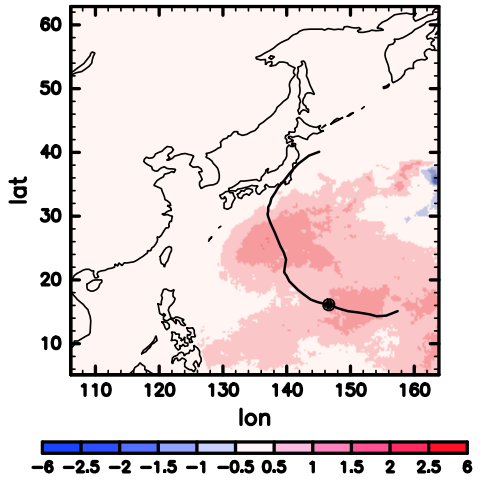

Fig. 1. (a) $\mathrm{SST}_{\text {warm }}$, (b) $\mathrm{SST}_{\text {warm }}-\mathrm{SST}_{\text {clim }}$, and (c) $\mathrm{SST}_{\text {warm }}-\mathrm{SST}_{\text {cold }}$ on 7 October 2019. The track of TC Hagibis in the best track is indicated by the thick solid line. The closed black circle indicates the center position of TC Hagibis at 1200 UTC on 7 October 2019.

(a) Warm run

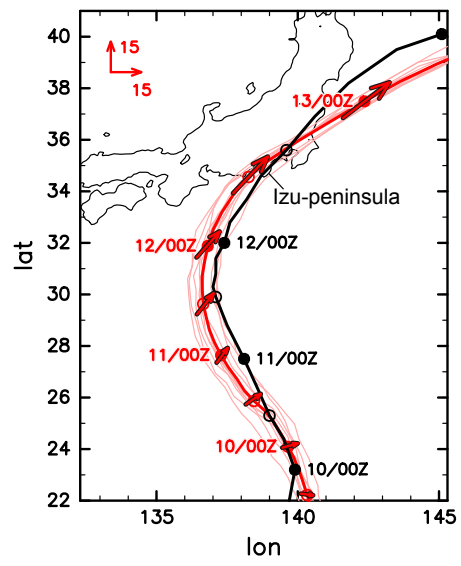

(c) Zonal translation speed

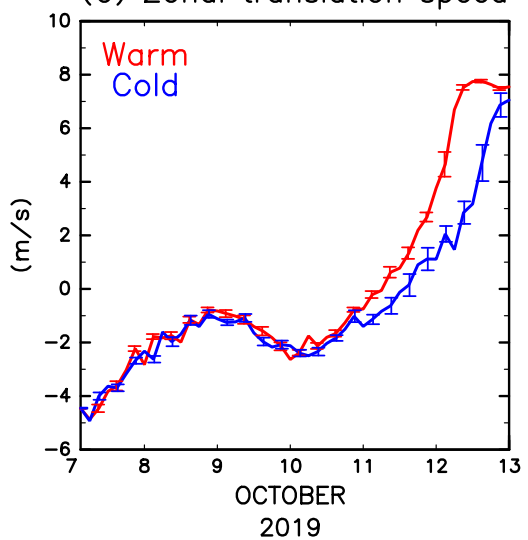

(b) Cold run

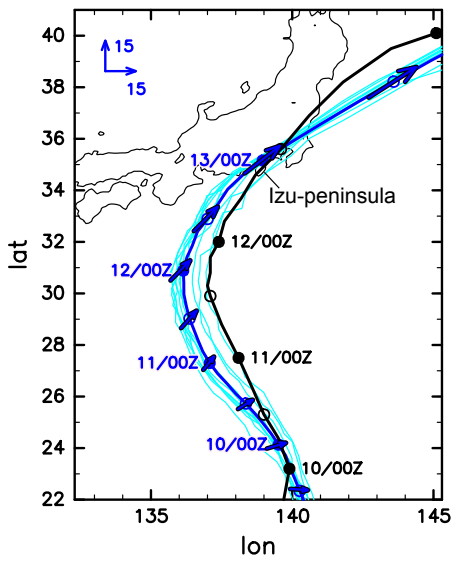

(d) Meridional translation speed

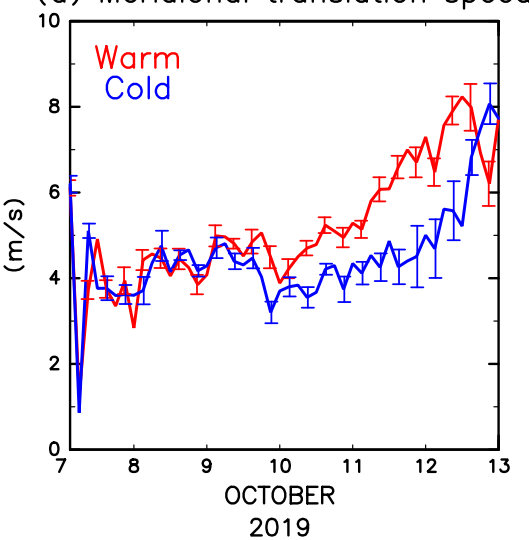

Fig. 2. Track of TC Hagibis simulated in (a) the warm run and (b) the cold run. The thin lines with light colors indicate the track in each ensemble member, whereas the thick line with strong color indicates the ensemble-mean track. The black solid line indicates the best track. Closed and open circles indicate the TC center position at 0000 UTC and 1200 UTC each day, respectively. The vertical wind shear in $\mathrm{m} \mathrm{s}^{-1}$ is indicated by the vectors, with the unit vector displayed in the upper-left of the panel. TC translation speed in $\mathrm{m} \mathrm{s}^{-1}$ in (c) zonal and (d) meridional directions from 1200 UTC 7 October to 1200 UTC 13 October. The standard error estimated by the ensemble spread is shown as error bars. The ticks in the $x$-axis were plotted for 1200 UTC in each day in $(\mathrm{c}-\mathrm{d})$.
$I^{2}$, defined as follows:

$$
I^{2}=\left(f+\frac{\bar{v}}{r}+\frac{\partial \bar{v}}{\partial r}\right)\left(f+\frac{2 \bar{v}}{r}\right)
$$

where $f$ is Coriolis parameter, $\bar{v}$ is tangential wind in a gradient-wind balance, and $r$ is the distance from the center of TC. The radial wind, $u$, as an agradient perturbation component, follows Eq. (5):

$$
\frac{\partial^{2} u}{\partial t^{2}}+I^{2} u=0
$$

Thus, the radial motion exhibits a horizontally coherent structure for weakly positive $I^{2}$ and the strong horizontal divergence tends to appear in the upstream region of negative $I^{2}$ (See supplemental material B for more details).

\section{Results}

Figure 2a shows that the ensemble-mean track of the warm run reasonably reproduced the Regional Specialized Meteorological Center Tokyo best track (hereafter, referred to as best track). Comparing Fig. 2a and Fig. 2b, the ensemble-mean TC center position in the cold run was almost the same as that in warm run until 0000 UTC 10 October. However, TC Hagibis in the warm run tended to move faster to the north and east during 10-11 Octo- 
(a) Vmax

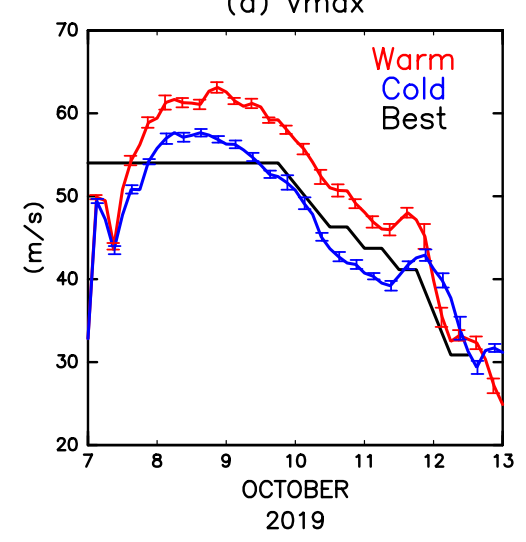

(a) OOUTC 100ct

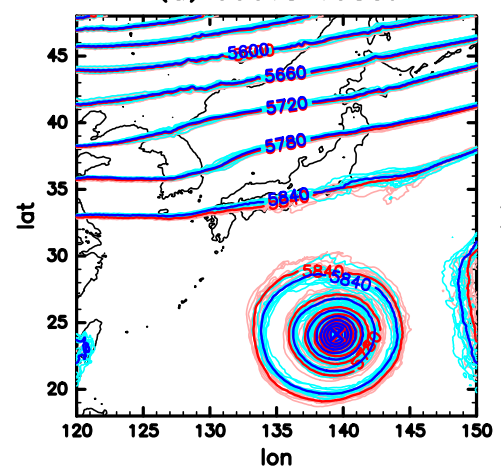

(d) 12UTC 110ct

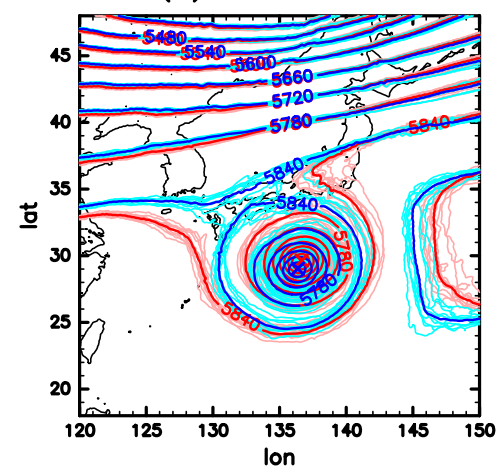

(b) R15

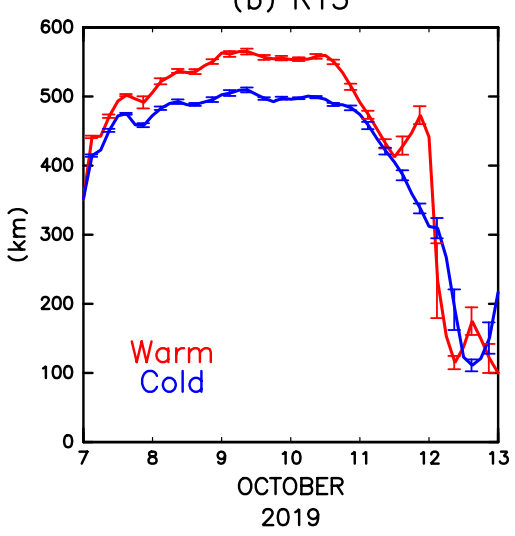

(b) 12UTC 100ct

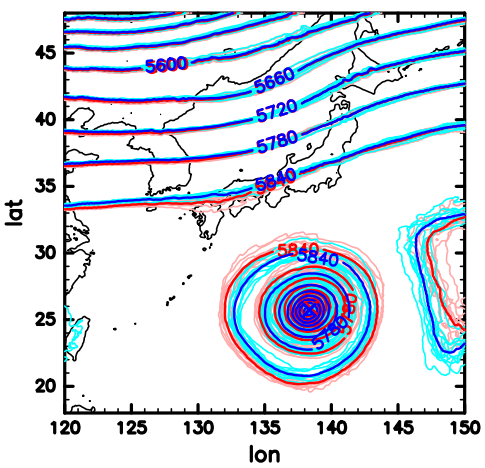

(e) OOUTC 120ct

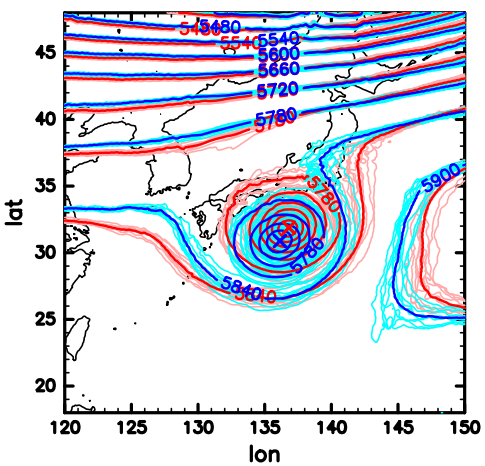

Fig. 3. Same as Figs. $2 \mathrm{c}$ and $2 \mathrm{~d}$ but for (a) the maximum wind speed and (b) the radius of $15 \mathrm{~m} \mathrm{~s}^{-1}$ wind at the $10-\mathrm{m}$ height. The surface maximum wind of the best track is also shown in Fig. 3a.

Fig. 4. Spaghetti diagrams of Z500. The thick red (blue) contours indicate the ensemble-mean values for the warm (cold) runs, whereas the thin pink (cyan) contours indicate the values in each ensemble member for the warm (cold) runs. The contour interval is $60 \mathrm{~m}$. The ensemble-mean TC center position is indicated by crosses.

ber than in the cold run, and it was further accelerated in the warm run on 12 October (Fig. 2). The difference in the translation speed was remarkable during 11-12 October in the warm and cold run (Figs. 2c and 2d), even though the trajectories heavily overlapped during this period (except for the westward position bias in the cold run). The ensemble-mean TC center position made landfall on the Izu-peninsula at 1500 UTC on 12 October in the warm run. Landfall was significantly delayed (0000 UTC on 13 October) in the cold run. The ensemble-mean TC center positions of the warm and cold runs were separated by only $15 \mathrm{~km}$ on 0000 UTC 10 October, but this displacement reached $400 \mathrm{~km}$ on 0000 UTC 13 October. A paired-sample two-tailed $t$-test showed that the faster TC translation speed in the warm run compared to the cold run was always statistically significant at a $95 \%$ confidence level from 2100 UTC on 10 October through until 0300 UTC on 13 October (Figs. 2c and 2d). As for the TC intensity and size, the warm run yielded the stronger and larger TC, in which the size was defined as the radius of surface wind of $15 \mathrm{~m} \mathrm{~s}^{-1}$, than the cold run before the landfall (Fig. 3). The warm SST was preferable for supplying energy to the TC, which reduced the convective stability.

The difference of translation speed is worth investigating. Figure 4 shows the geopotential height at $500 \mathrm{hPa}(\mathrm{Z} 500)$ from 0000 UTC 10 October through until 1200 UTC 12 October. From 0000-1200 UTC 10 October, the closed contours of $5840 \mathrm{~m}$ indicate the expansion of the outer region of TC Hagibis in the warm run. Another remarkable difference was the retreat of the subtropical high indicated at $5900 \mathrm{~m}$ in the warm run, as simulated by Sun et al. (2017). These changes were previously discernible at 0000 UTC 9 October (figures not shown), but the TC center positions of the warm and cold runs remained almost the same until 1200 UTC 10 October (Figs. 4a and 4b). In fact, the subtropical high retreat cannot explain the faster northward motion in the warm run because the larger contour interval of Z500 indicated the weakening of the synoptic-scale northward steering flow. This 
(a) OOUTC 100ct

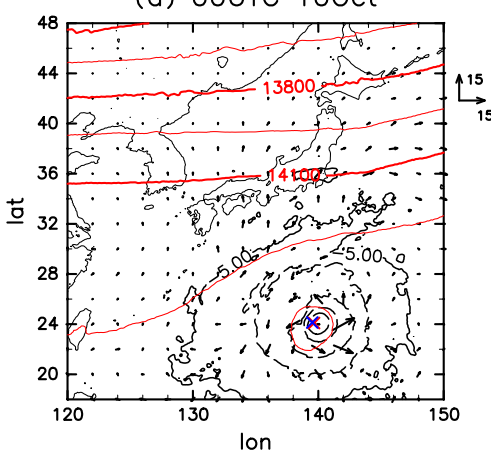

(d) 12 UTC 110 ct

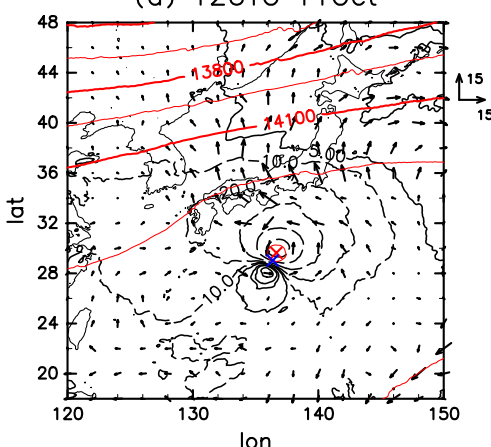

(b) 12 UTC 100ct

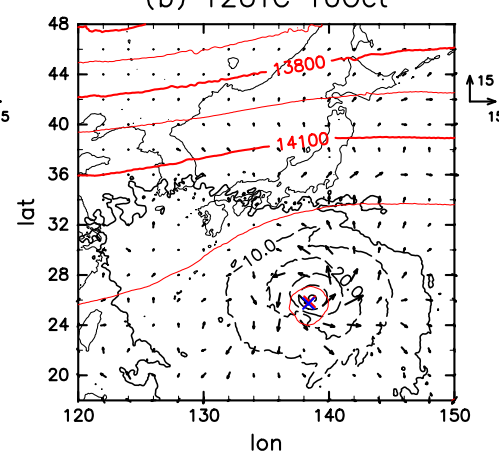

(e) OOUTC $120 \mathrm{ct}$

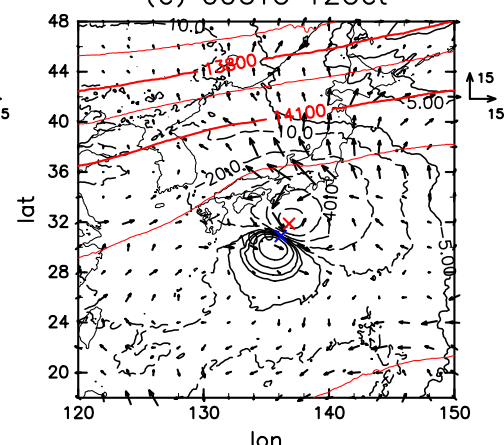

(c) OOUTC $110 \mathrm{ct}$

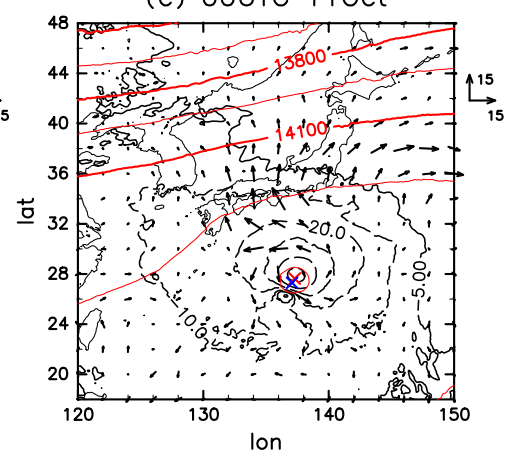

(f) 12 UTC 120ct

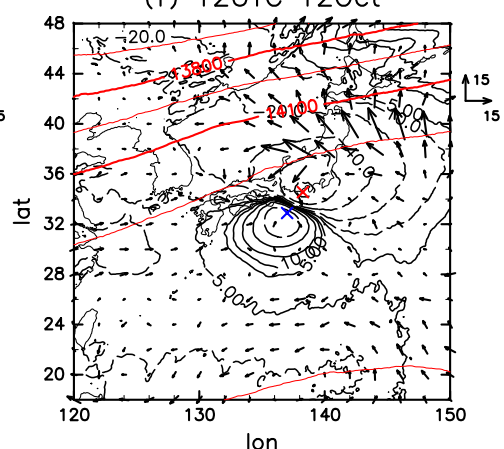

Fig. 5. Difference in Z500 between the warm and cold runs (black contours). The black contours are drawn for $\pm 5, \pm 10, \pm 20, \pm 40, \pm 80$, and $\pm 160 \mathrm{~m}$. The geopotential height at $150 \mathrm{hPa}$ in the warm run is also drawn in red contours with the contour interval of $150 \mathrm{~m}$. The ensemble-mean TC center positions in the warm (cold) runs are indicated by red (blue) crosses. The wind differences between the warm and cold runs at $150 \mathrm{hPa}$ are indicated by vectors. The unit vector is shown in the right-hand side of each panel in $\mathrm{m} \mathrm{s}^{-1}$.

was different from the situation of Sun et al. (2017), in which the westward wind of the subtropical high turned into the northward wind due to the retreat. At 0000 UTC 11 October, the $5840 \mathrm{~m}$ contour in the southern tip of the mid-latitude westerly was displaced by approximately $100 \mathrm{~km}$ to the south in the warm run. The closed $5840 \mathrm{~m}$ contour was also bulged in the north of TC Hagibis (Fig. $4 \mathrm{c})$. This implies that the pressure decreased in the northern side of TC in the middle-troposphere. At 1200 UTC 11 October, Z500 further decreased in the north of TC Hagibis. This decrease was more pronounced in the warm run, in which the $5840 \mathrm{~m}$ contour connected the westerly and TC Hagibis. In contrast, these two contours were still separated in the cold run (Fig. 4d). After TC Hagibis in the warm run was embedded in the westerly, it experienced acceleration to the northeast, in comparison with the cold run (Figs. $4 \mathrm{e}$ and $4 \mathrm{f}$ ).

The anomaly of Z500 and wind field at $150 \mathrm{hPa}$ in the warm run (relative to the cold run) from 0000 UTC 10 October to 1200 UTC 12 October is shown in Fig. 5, with the geopotential height at $150 \mathrm{hPa}$. At 0000 UTC 10 October, the largest decrease of Z500 in the warm run was slightly in the southeast of the TC center. The decrease of Z500 indicated the decrease of airmass aloft, and it corresponded to the stronger southeastward upperlevel outflow anomaly in the south of the TC (Fig. 5a). This was presumably because the small $f$ yielded the lower $I^{2}$ in the south (Komaromi and Doyle 2018). At 1200 UTC 10 October, a larger decrease in Z500 appeared to the north of the TC, and the decrease of geopotential height field in the north had a vertically coherent structure between $200 \mathrm{hPa}$ and the surface (figures not shown). This was supported by the northward anomaly of the upper-tropospheric outflow as stronger divergence in the north of TC Hagibis (Fig. 5b). The TC began to interact with the upper-tropospheric westerly jet and moved northwards faster in the warm run at this time (Figs. 2 and 5b). The significant decrease of the geopotential height (or the pressure) in the north served to displace the TC center to the north. Note that the anomaly of cyclonic circulation at $500 \mathrm{hPa}$ was accompanied with the maximum decrease in Z500 in the north of the TC center (figures not shown), and it yielded the westerly wind anomaly to steer the TC further. Therefore, this decrease in Z500 was consistent with the displacement of TC in the warm run. That is, the sensitivity experiment exhibited the acceleration to the north and then to the northeast in the warm run. At 0000 UTC 11 October, the decrease in Z500 in the warm run was further biased towards the north of the TC, supported by the stronger northward outflow (Fig. 5c). This situation continued in the later period until the landfall. Evidently, the northward displacement of a TC yields the dipole pattern of northern negative and southern positive in the anomalous geopotential field. However, the northern biased decrease of Z500 with the stronger northward outflow cannot be merely explained by the displacement of TC center position until 1200 UTC 10 October, as the displacement of the TC center position was negligible. One may speculate that this northward motion is due to the enhanced beta gyre effect in the warm run on 1200 UTC 10 October. However, there was no evident dipole pattern of negative vorticity anomaly in the east and positive vorticity anomaly in the west, which consist of the northward steering wind in a beta gyre concept, in a TC-centered coordinate (figures not shown).

The enhanced convection in the stronger and larger TC of the warm run presumably preferred the upper-level northward outflow anomaly that yielded the Z500 decrease. To investigate this feature, Figs. $6 \mathrm{a}-6 \mathrm{~d}$ show the storm-relative wind field averaged from 1200 UTC 10 October to 0000 UTC 12 October in the north, west, south, and east quadrants of the warm run. The TC outflow between 100-300 $\mathrm{hPa}$ was strongest in the northern quadrant, as was the upward motion in the inner core; this was followed by the eastern quadrant. This presumably depended on (1) the direction of vertical wind shear and (2) the local inertial stability.

Regarding the approach to the westerly jet, the vertical wind shear (defined as the wind vector difference between 850 and $200 \mathrm{hPa}$ of the wind fields, averaged for the distance between 200 and $800 \mathrm{~km}$ ) was aligned northeastward during this period (Fig. 2a). Therefore, the convection was much stronger in the north of 
(a) N: Wind(Warm)

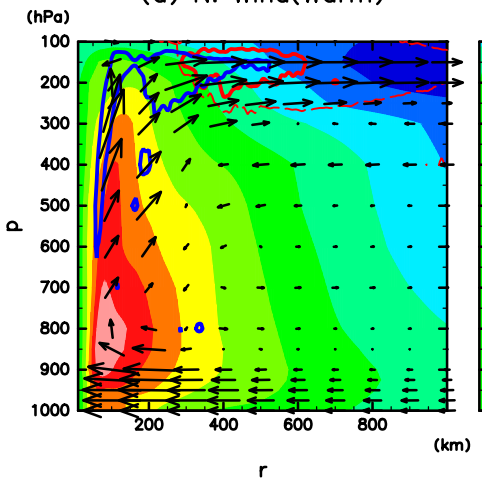

(b) W: Wind(Warm)

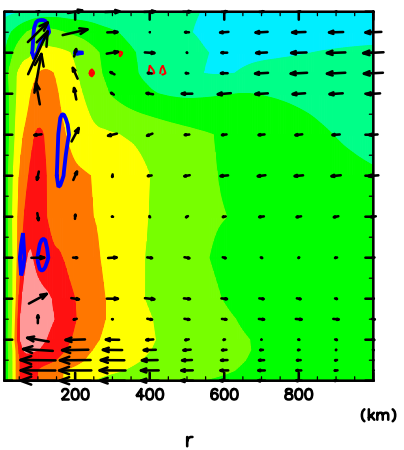

(c) S: Wind(Warm)

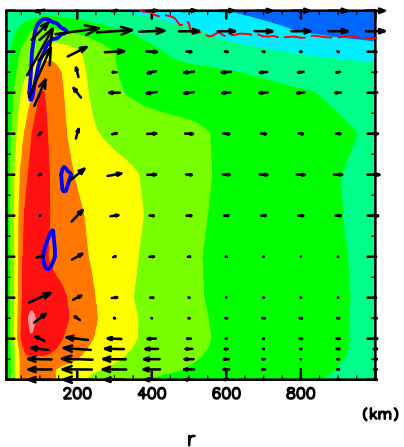

(d) E: Wind(Warm)

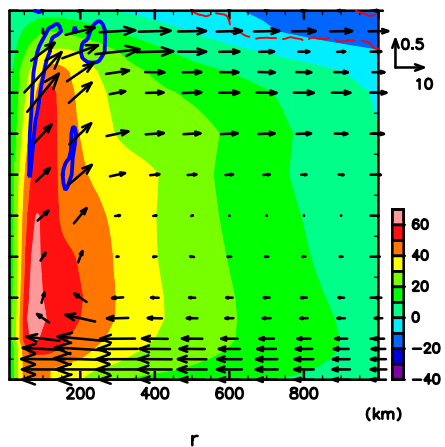
$\left(\begin{array}{cc}(e) \\ (n P o)\end{array}\right.$
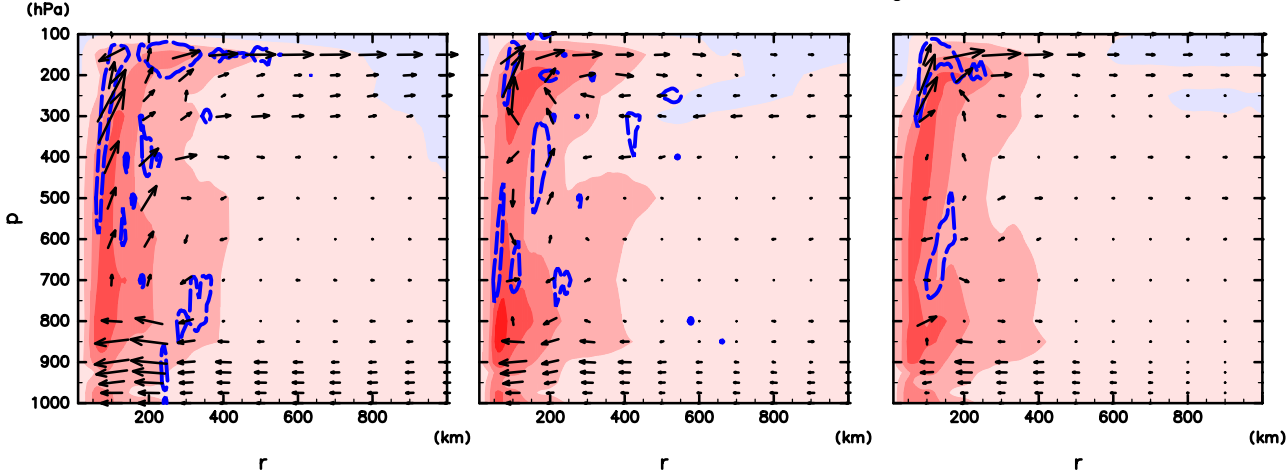

(h) E: Wind(Warm)-Wind(Cold)

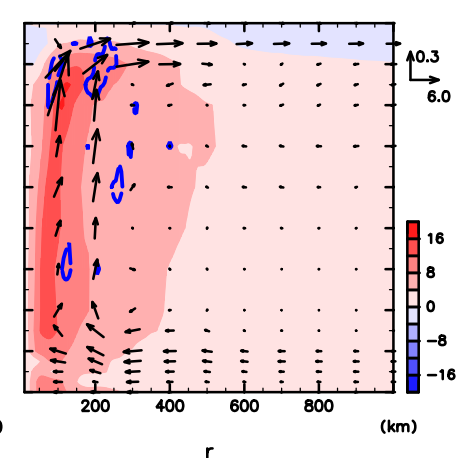

Fig. 6. Quadrant-mean storm-relative wind field in radial-pressure coordinates. (a-d) $v$ (shadings) and $(u, w)$ (vectors) in $\mathrm{m} \mathrm{s}^{-1}$ in the warm run, where $w$ is vertical velocity. (e-h) Anomaly of $v$ (shadings) and $(u, w)$ (vectors) in the warm run with respect to the cold run. (a, e) North quadrant (from northeast to northwest), (b, f) west quadrant (from northwest to southwest), (c, g) south quadrant (from southwest to southeast), and (d, h) east quadrant (from southeast to northeast). The thin broken and thick solid red contours in (a)-(d) indicate the boundaries of $I^{2}=(0.5 f)^{2}$ and $I^{2}=0.0$, respectively. The solid blue contours in in (a)-(d) indicate the boundaries of the radius-weighted horizontal divergence $\left(\partial(u r) / \partial r+\partial v / \partial \phi ; \phi\right.$ is azimuthal angle) of $16.0 \mathrm{~m} \mathrm{~s}^{-1}$, while the broken blue contours in $(\mathrm{e})-(\mathrm{h})$ indicate the boundaries of the radius-weighted horizontal divergence anomaly of $8.0 \mathrm{~m} \mathrm{~s}^{-1}$.
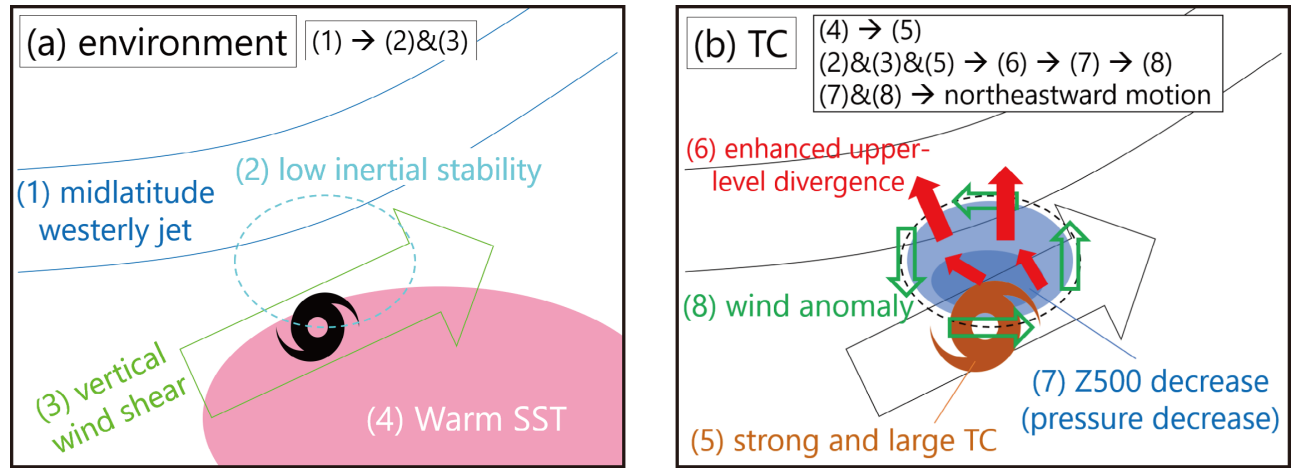

Fig. 7. Schematic illustration of (a) environmental conditions and (b) TC Hagibis that brought about the northeastward displacement in the warm run.

TC, due to the downshear to downshear-left quadrant (Rogers et al. 2013; Ueno and Kunii 2009). This contributed to the enhanced upward mass flux and outflow.

The midlatitude westerly jet made $I^{2}$ lower in the upper troposphere of the northern quadrant than in the other quadrants (Figs. $6 \mathrm{a}-6 \mathrm{~d})$. This supports the idea that the preferred outflow was northwards. In particular, the negative $I^{2}$ indicates that the outflow tended to cause the horizontal divergence in the north. This result is consistent with previous studies, which have showed that there is lower $I^{2}$ between a TC and a mid-latitude westerly jet in the north (Kitabatake 2002; Komaromi and Doyle 2018; Saito 2019), because the jet-induced negative $\bar{v}$ gives a small $I^{2}$, according to Eq. (4).

Figures $6 \mathrm{e}-6 \mathrm{~h}$ show the anomaly of the storm-relative wind field in the warm run, relative to the cold run, corresponding to the period shown in Figs. 6a-6d. The stronger TC generally increased the upward mass flux from the inner core and the outflow in the upper troposphere in all quadrants, contributing to the decrease in Z500. This change was most pronounced in the northern quadrant, where the outflow tended to be horizontally coherent or accelerated due to lower $I^{2}$ under the particularly enhanced convective activity in the downshear to downshear-left. These results suggest that the approach of TC Hagibis to the westerly jet in the north constructed the preferential pathway of the northward outflow. The enhanced outflow in the warm run used this pathway and thus the enhanced upper-level divergence especially decreased the Z500 in the north of TC.

The results can be summarized as follows (Fig. 7). The warm SST energized TC Hagibis, so that it enhanced the upward mass flux. This led to the strong outflow in the upper-troposphere. 
Regarding the approach of the westerly jet, the enhanced TC outflow was preferentially directed northward, because, in the north of the TC, the jet-induced northeastward vertical wind shear supported stronger convection and the upper tropospheric westerly winds contributed to the lower $I^{2}$. Thus, the stronger upper-level divergence led the significant decrease in Z500 in the north. This caused the northeastward displacement of the TC, due to the decrease of pressure to the north and the anomalous westerly flow steering the TC. As such, TC Hagibis in the warm run was embedded in the mid-latitude westerly jet earlier, and experienced faster northeastward motion, compared to the cold run.

\section{Conclusions}

As the anomalous SST was one of the major environmental characteristics of TC Hagibis, here we conducted a sensitivity experiment to investigate the impact of this SST anomaly in the WNP. To obtain a reliable result, each ten-member ensemble simulation was conducted with a JMA-NHM. The experiment showed that warm SST accelerated TC Hagibis when it approached to the mainland Japan, as TC Hagibis was embedded earlier into the synoptic scale mid-latitude westerly jet. The displacement of the TC center position reached $400 \mathrm{~km}$. The motion was highly correlated to the middle tropospheric field, which was consistent with the substantial decrease in Z500 in the north of the TC. Further analysis showed that the large decrease of Z500 in the warm run could be accounted for by the stronger outflow observed in the north of TC Hagibis. The approach to the westerly jet yielded vertical wind shear directed to the northeast, and there was low local inertial stability in the north of the TC. These conditions were suitable for the enhanced northward upper-level outflow in the north of the TC in the warm run, because the high SST made the TC large and intense. Perhaps this mechanism also explains the northward motion of a TC when approaching to a mid-latitude trough (Komaromi and Doyle 2018). Recent studies such as Katsube and Inatsu (2016) and Sun et al. (2017) have basically ascribed the warm SST-related northward displacement and earlier recurvature to the retreat of a subtropical high, or to the thermal response to a persistent heating source. In this study, we propose another possible route to explain the change in the TC track, namely interaction with a westerly jet as a response to SST warming. To validate the versatility of the current mechanism and address the remaining issues, more case studies are required in future studies. Furthermore, we need to note that the initial atmospheric condition as a response to SST change was not adjusted in the current experiment. It means that this experiment did not fully account for the impact of climate change.

\section{Acknowledgments}

We thank Drs. K. Saito, M. Yamaguchi, S. Hirano, and W. Yanase for providing us the useful comments. The current work is supported by MEXT KAKENHI Grant $18 \mathrm{H} 01283$. This work was also supported by MEXT as "Program for Promoting Researches on the Supercomputer Fugaku" (Large Ensemble Atmospheric and Environmental Prediction for Disaster Prevention and Mitigation, ID:hp200128/hp120279) and used computational resources of the High Performance Computing Infrastructure (HPCI) system provided by the RIKEN R-CCS and Oakforest-PACS.

Edited by: J. Yoshino

\section{Supplement}

Supplementary materials include 1 figure.

\section{References}

Emanuel, K. A., 1986: An air-sea interaction theory for tropical cyclones. Part I: Steady-state maintenance. J. Atmos. Sci., 43, 585-605.

Hoskins, B. J., and D. J. Karoly, 1981: The steady linear response of a spherical atmosphere to thermal and orographic forcing. J. Atmos. Sci., 38, 1179-1196.

Ikawa, M., and K. Saito, 1991: Description of a nonhydrostatic model developed at the Forecast Research Department of the MRI. Technical Reports, 238 pp.

Kain, J. S., and J. M. Fritsch, 1990: A one-dimensional entraining/ detraining plume model and its application in convective parameterization. J. Atmos. Sci., 47, 2784-2802.

Katsube, K., and M. Inatsu, 2016: Response of tropical cyclone tracks to sea surface temperature in the western North Pacific. J. Climate, 29, 1955-1975.

Kitabatake, N., 2002: Extratropical transformation of Typhoon Vicki (9807): Structural change and the role of uppertropospheric disturbances. J. Meteor. Soc. Japan. Ser. II, 80, 229-247.

Kitagawa, H., 2000: Radiation processes. Separate Volume of Annual Report of JMA-NPD, 46, 16-31.

Knutson, T. R., and co-authors, 2010: Tropical cyclones and climate change. Nature Geosci., 3, 157-163.

Komaromi, W. A., and J. D. Doyle, 2018: On the dynamics of tropical cyclone and trough interactions. J. Atmos. Sci., 75, 2687-2709.

Kurihara, Y., M. A. Bender, and R. J. Ross, 1993: An initialization scheme of hurricane models by vortex specification. Mon. Wea. Rev., 121, 2030-2045.

Nakanishi, M., and H. Niino, 2004: An improved Mellor-Yamada level-3 model with condensation physics: Its design and verification. Bound.-Layer Meteor., 112, 1-31.

Rogers, R., P. Reasor, and S. Lorsolo, 2013: Airborne Doppler observations of the inner-core structural differences between intensifying and steady-state tropical cyclones. Mon. Wea. Rev., 141, 2970-2991.

Saito, K., 2012: The JMA Nonhydrostatic model and its applications to operation and research. InTech. Atmos. Model Appl., 85-110.

Saito, K., 2019: On the northward ageostrophic winds associated with a tropical cyclone. SOLA, 15, 222-227.

Saito, K., and co-authors, 2006: The operational JMA nonhydrostatic mesoscale model. Mon. Wea. Rev., 134, 1266-1298.

Sun, Y., and co-authors, 2017: Impact of ocean warming on tropical cyclone track over the western north pacific: A numerical investigation based on two case studies. J. Geophys. Res. Atmos., 122, 8617-8630.

Ueno, M., and M. Kunii, 2009: Some aspects of azimuthal wavenumber-one structure of typhoons represented in the JMA operational mesoscale analyses. J. Meteor. Soc. Japan, 87, 615-633.

Yabu, S., S. Murai, and H. Kitagawa, 2005: Clear sky radiation scheme. Separate Volume of Annual Report of JMA-NPD, 51, 53-64 (in Japanese).

Manuscript received 5 June 2020, accepted 17 August 2020

SOLA: https://www.jstage.jst.go.jp/browse/solal 